\title{
A contribuição da Sociologia à compreensão de uma epistemologia complexa da Ciência contemporânea
}

\author{
LÉO PEIKOTO RODRIEUES" \\ FABRÍCIO MONTEIRO NEUES: \\ JOSÉ GARLOS DOS ANJOS"
}

\section{Resumo}

Este artigo parte de um breve relato crítico sobre as questões epistemológicas centrais que se colocaram no decorrer do século XX e que afetaram tanto as ciências naturais como as ciências sociais. Inicia por retomar, de forma breve, os principais pontos do debate, em seu caráter analítico, e apresentar suas consequências, principalmente aquelas relativas ao enfraquecimento da dicotomia entre ciências sociais e ciências naturais. Com a crise da epistemologia analítica, no final da década de 1960, e com a emergência das abordagens complexas, em detrimento daquelas determinísticas, as ciências sociais passaram a ampliar seus questionamentos aos fundamentos da ciência tradicional, de forma transdisciplinar. $\mathrm{O}$ artigo busca, também, indicar caminhos para transcender as limitações da epistemologia clássica, ao oferecer um quadro das novas discussões pós-coloniais e suas consequências, em especial aos dualismos universal/local, social/natural, corporal/simbólico.

Palavras-chave: Epistemologia. Ciências sociais. Conhecimento. Complexidade. Pós-estruturalismo. Desconstrução. Pós-colonial.

\footnotetext{
Universidade Federal de Pelotas (Brasil)

${ }^{* *}$ Universidade de Brasília (Brasil)

${ }^{* * *}$ Universidade Federal do Rio Grande do Sul (Brasil)
} 
Sociologias, Porto Alegre, ano 18,no 41, jan/abr 2016, p. 24-53

\section{The contribution of sociology to the understanding of a complex epistemology of contemporary science}

\section{Abstract}

This article starts with a brief critical account of the major epistemological issues that emerged during the twentieth century and that affected both the natural sciences and the social sciences. It briefly resumes the main matters of contention from the analytical view, and presents its consequences, particularly those related to the weakening of the dichotomy between social sciences and natural sciences. Following the crisis of analytical epistemology, in the late 1960s, and the emergence of complex approaches to the detriment of deterministic ones, social sciences have begun to expand their questioning the foundations of traditional science in a transdisciplinary way. The article also seeks to indicate ways to overcome the limitations of classical epistemology, by providing an account of the new postcolonial debates and their consequences, particularly the dualisms universal/local, social/ natural, physical/symbolic.

Keywords: Epistemology. Social Sciences. Knowledge. Complexity. Post-structuralism. Deconstruction. Postcolonial.

\section{Um ponto de partida: a epistemologia linear e a sua contestação (autorreflexiva) na primeira metade do século XX}

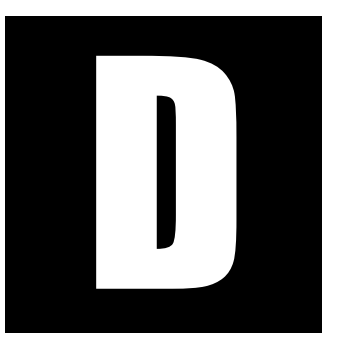

esde o advento da Ciência moderna, poderíamos afirmar com certo grau de certeza, o Século XX foi aquele em que epistemologia mais esteve em evidência como objeto de debate e de controvérsia no cenário intelectual. Nunca antes, para além da filosofia - e mesmo dentro da filosofia - tantas correntes, escolas e disciplinas estiveram tão empenhadas em verificar como a ciência poderia garantir - e se de fato o fazia - o conhecimento científico, questionando as suas premissas básicas, o seu fundamento. 
A prática da Ciência, desde sua origem, tem privilegiado perspectivas epistemológicas que se sustentam, se amparam, em importante medida, na noção de causalidade (todo efeito tem uma causa, toda causa gera um efeito). Essa forma da ciência de falar sobre os "objetos do mundo" terá correspondência naquilo que a matemática tem chamado de linear ou de linearidade, posto que os fatores causais podem ser identificados (isolados e conhecidos) no tempo e no espaço. A Ciência conseguiu, numa imbricada relação com aquilo que se chamou de Modernidade (e que se confunde com ela própria) dar respostas e solucionar uma série de problemas a ela apresentados, fazendo com que tais explicações/soluções "funcionassem" no cotidiano da vida social. A Ciência, baseada na lógica clássica, aristotélica, além do seu enfoque causal, aderiu centralmente a uma epistemologia específica, para a qual existe um mundo objetivo (e objetivado) fora (e independente) do ente que o observa, e que se mostra de forma única (e verdadeira) a todos observadores ${ }^{1}$. Isso lhe permitiu estabelecer "certezas" e "verdades" quase-únicas (ou consensuais) acerca do mundo. A partir disso, a Ciência conduziu à crença de que o conhecimento científico (como teoria e modelos) tinha correspondência com a realidade observada; de que o todo observado ${ }^{2}$ constitui-se na totalidade das observações possíveis; e de que a totalidade da "realidade externa" só

\footnotetext{
${ }^{1}$ Não vamos problematizar aqui, por falta de espaço, importantes aspectos do debate (metafísico) que se tem travado, mesmo no século XX, sobre "mundo interno" e "mundo externo", idealismo e realismo. Sugerimos, para tanto, ver: "Positivismo e Realismo" de Moritz Schlick (1975); "Realismo", " Metafísica e Criticabilidade", de Karl Popper (2010).

${ }^{2}$ Aqui e sempre que mencionamos o termo "observação", estamos vinculando-o ao sentido desenvolvido pela cibernética, em um primeiro momento e, posteriormente, pelas ciências da cognição, em que o termo significa sempre "uma operação de distinção entre os objetos do mundo". Em outros termos, para essas ciências, observar exige sempre um observador (que pode ser humano ou não e que é chamado genericamente de sistema, incluindo máquinas) e um observado, estabelecendo-se assim, nessa relação, uma operação de distinção, de diferenciação. Para essas ciências, não pode existir distinção sem observação e, de outro modo, tudo aquilo que é observado é a fortiori diferenciado. Para um aprofundamento ver: Foerster (2006); Plotnitsky (2010); Wiener; Schadé (1965).
} 
opera no nível da observação humana, tornando-se o humano a medida de toda a realidade do mundo que, cartesianamente, é externa e ele.

Foi a partir dos questionamentos dessas premissas estabelecidas pela ciência, em boa medida ditadas pela filosofia, e que compuseram o seu mainstream, que a Epistemologia passa a se autonomizar com relação à filosofia ${ }^{3}$. O século XX foi também o período no qual a Epistemologia passou a ser acolhida, com legitimidade, pelas diferentes disciplinas que integram a Ciência.

Para retomarmos brevemente um ponto de partida dessa história epistemológica, podemos iniciar pela sistematização da disciplina que hoje conhecemos por filosofia da ciência, surgida no início do século XX, a partir do Círculo de Viena, cujo enfoque epistemológico ficou conhecido como positivismo lógico, termo este que se confunde com o próprio nome dessa corrente ${ }^{4}$. No decorrer das primeiras décadas do Século XX, a filosofia da ciência consolida-se e se institucionaliza como uma corrente de pensamento independente (ou quase) da filosofia. O Círculo de Viena teve um papel protagonista nesse desdobramento, posto que o positivismo lógico se constituía num tipo de especialização da filosofia para tratar especificamente da Ciência. O positivismo lógico, portanto, como arcabouço epistemológico, constituiu-se na expressão máxima da visão filosó-

\footnotetext{
${ }^{3}$ Essa perspectiva também tem sido chamada, no âmbito da epistemologia, de "realismo empirista"; mais tarde, de "empirismo realista ingênuo".

${ }^{4} \mathrm{O}$ positivismo lógico constituiu-se numa variante do pensamento filosófico (analítico) voltado à Ciência. Como motor de uma corrente de pensamento, o Círculo de Viena, ele se propunha a se autonomizar da reflexão sobre a ciência, dominada ainda pela filosofia, então chamada de "filosofia tradicional". O Círculo de Viena, iniciado pelo físico Philipp Frank, o matemático Hans Hahn e o economista Otto Neurath, que se reuniam regularmente na Universidade de Viena para discutir temas relacionados à filosofia da ciência, à lógica, à teoria do conhecimento e à linguagem, tinha como objetivo "a propagação e progresso de uma visão científica do mundo e a criação de instrumentos intelectuais do empirismo moderno" (Pérez, 2003, p. 169), destacando a sua postura radicalmente empirista e a-metafísica. Existem excelentes textos dobre esse movimento, aqui indicaremos Reisch (2009); Städler (2010); esta última, uma das mais completas obras sobre "O Círculo de Viena", com quase 1000 páginas.
} 
fica analítica de Ciência. Esta visão ficou conhecida como a "Concepção Herdada"5, apropriadamente resumida por Palma (1998, p. 56): "Para a Concepção Herdada, a tarefa da filosofia da ciência consiste na análise, isto é, na reconstrução da estrutura lógica das teorias científicas mediante métodos matemáticos [para intervir] nas suas crises de fundamento".

Esse caldo filosófico-epistemológico, nas primeiras três décadas do Século XX, também envolveu a Sociologia. Para Karl Mannheim6, sociólogo alemão, o conhecimento a ser estudado pela Sociologia do Conhecimento deveria ser aquele emanado, inconscientemente, por toda uma sociedade ou um grupo social e que, por conseguinte, diferenciava-se de um grupo social para outro; de sociedade para sociedade, mudando em conformidade com as diferentes bases existenciais de cada sociedade. Para ele, as verdades e falsidades deveriam estar sempre vinculadas a uma perspectiva relacional (Mannheim, 1982, p. 81). Em seu trabalho "Ideologia e Utopia" ([1929]1982), a Sociologia do Conhecimento é sistematizada e convocada a compreender a distinção entre "ideologia particular" e "ideologia total", além de identificar os fatores condicionantes dessa última, posto que ela sempre estaria condicionada por um contexto social específico, que estrutura as categorias de pensamento e a "concepção total de mundo" de determinados grupos.

\footnotetext{
${ }^{5} \mathrm{O}$ termo "Concepção Herdada" surgiu em língua inglesa, Received View, logo após o contexto da publicação de "Estrutura das Revoluções científicas", de Thomas Kuhn, ([1962]1996). Putnam, um dos principais críticos do positivismo denominou essa corrente de pensamento analítico, que se havia ampliado e enriquecido sob a interação com diversas linhas de pensamento. O termo passou a ser utilizado para caracterizar uma perspectiva sobre a ciência em que essa se apresentava como se fosse imune ao contexto social; compreendida como autossuficiente, e autoexplicativa; praticamente blindada do meio (social, cultural, político e econômico) onde realizava a sua atividade de "gerar" conhecimento (Rodrigues, 2005).

${ }^{6}$ Karl Mannheim foi discípulo de Alfred Weber e posteriormente professor da Universidade de Frankfurt, colega de Theodor W. Adorno e de Max Horkheimer. Ele migrou para a Grã-Bretanha, indo lecionar na London School of Economics, durante o período de 1933-1945.
} 
Se, por um lado, a filosofia tradicional, como mencionamos anteriormente, no que concerne à sua metafísica e aos seus pressupostos epistemológicos, foi criticada pelo Círculo de Viena a ponto de propiciar a autonomização da epistemologia sob a rubrica de "filosofia da ciência", por outro lado, na década de 1930, mais especificamente a partir de $1934^{7}$, a própria filosofia da ciência tem o seu núcleo - ou seja, o indutivismo e o verificacionismo - fortemente abalado, com o ataque contundente realizado por Karl Popper ao positivismo lógico.

Karl Popper foi um dos primeiros filósofos da ciência implicado diretamente na crise do Positivismo Lógico. Em Logik der Forschung, datada de 1934, ele trazia a discussão de fundo filosófico-epistemológico, que vai se tornar clássica e objeto de acalorado debate durante todo o século XX. A importância dessa obra está no fato de que Popper enfrenta o "problema da indução" e declara a impossibilidade de essa constituir-se num método científico, lógico, como critério de produção de verdade e de demarcação entre ciência e não-ciência. Entretanto, Popper, ao retomar o argumento de Hume (a impossibilidade da indução), propõe uma saída "estratégica" para que se contorne o "problema da indução", por um lado, e se continue tendo um critério para a demarcação da ciência e da não ciência, por outro lado; isto é, uma "garantia" (mesmo que temporária) para a "veracidade" das teorias científicas: sua testabilidade e falseabilidade (Popper, 1974a; 1977).

Nas décadas que compreenderam 1940-60, a própria Filosofia da Ciência - dado o contínuo aumento do dissenso em torno de questões epistemológicas fundamentais - desdobra-se em duas: a filosofia tradicional da ciência e a nova filosofia da ciência. Alberto Oliva (2005, p. 50) bem resume a questão, quando afirma que: "O repto, entre outros,

\footnotetext{
${ }^{7}$ A pertinência ou não de Karl Popper ao Círculo de Viena (ou o nível de envolvimento que ele teve) é controvertida. Para o conhecimento dessas opiniões, ver: Popper (2010; 1977; 1974); Kuhn (2011; 2006; 1996; 1979); Städler (2010); Reisch (2009); Oliva (2005; 1999); Magee (1979).
} 
consiste em mostrar como a filosofia, cindida em Escolas [a filosofia tradicional, a filosofia tradicional da ciência e a nova filosofia da ciência], e marcada pelo dissenso crônico, pode se propor a elucidar o que é a Ciência e como se forma e se sustenta o consenso em torno de seus rituais e resultados [grifos nossos]".

A partir de então, muitos estudos voltados ao conhecimento, em geral, e ao debate sobre a ciência em específico vêm à tona através de diferentes teóricos, de variadas disciplinas. Ao final da década de 1950 e início dos anos 60, foi quando se consolidou o movimento que passou a ser conhecido como "nova filosofia da ciência", com os trabalhos de Polanyi, Toulmin, Quine, Feyerabend, Hanson e Kuhn, dentre outros ${ }^{8}$. Ao se referir a esses autores e à nova filosofia da ciência, Gupta (2004, p. 237) afirma que, embora estes autores apresentem divergências entre si, eles convergem em um ponto: "sua radical crítica ao positivismo lógico, frente à afirmação de que todos os fatos científicos existem 'aí fora', num mundo objetivo e independente de nós e do marco conceitual sob o qual são contemplados".

Se é justo afirmar-se que a nova filosofia da ciência vinha sendo delineada desde a crise do positivismo lógico e com os trabalhos que se seguiram logo no início da década de 1950, como mencionamos, não menos justo é dizer que ela surge com seu maior vigor a partir do revolucionário ensaio de Thomas Kuhn, "A estrutura das revoluções científicas", publicado em 1962, e seus renovados conceitos sobre como a ciência opera e se desenvolve; quais sejam: "Ciência Normal", "Revolução Científica" e "Paradigma".

\footnotetext{
${ }^{8}$ Não queremos aqui dar a ideia de que o positivismo lógico foi o movimento que caracterizou a filosofia tradicional da ciência e que, posteriormente ao seu declínio, emerge uma "nova filosofia da ciência"; não! As coisas, na história, inclusive da ciência, raramente se apresentam com rupturas radicais. Dentro do próprio positivismo lógico se formaram "programas rivais" no que se refere à filosofia tradicional da ciência, e que se intensificara ao final da II Guerra Mundial. Sobre estes programas ver Reisch (2009), especialmente os Capítulos 13 e 14.
} 
Thomas Kuhn, seguido de Popper, certamente foi o filósofo da ciência mais lido e mais criticado durante o século XX. Foi o teórico da Ciência, rivalizando com Popper, que mais desferiu golpes à chamada "concepção herdada". Para Oliva, (1999, p. 45) "os diferentes tipos de crítica que Popper e Kuhn movem à "Received View", quase todas estribadas em princípios e pressupostos da gnosiologia empirista, modelam diretamente seus modos de conceber a relação entre Ciência e Sociedade". De fato, depois de Popper e de Kuhn, mesmo tendo se passado quase 30 anos das principais publicações de um e de outro ${ }^{9}$, sobretudo a partir da década de 1970, a filosofia da ciência passa a contemplar (e debater) uma série de questionamentos sobre o papel de fatores sócios-culturais na produção do conhecimento científico, questionando, assim, a divisão proposta por Hans Reichenbach entre "internalismo" e "externalismo", bem como a fundamentação empírica como garantidora da estrutura lógica das teorias científicas e de suas explicações sobre os objetos do mundo.

\section{As ciências sociais e as ciências naturais: uma dicotomia irrelevante frente à complexidade epistemológica contemporânea}

Na sociologia, a produção de teoria - como modelos científicos que buscam explicar, descrever, representar os fenômenos sociais - desde seus primórdios, seja com Auguste Comte, com Emile Durkheim ou com Herbert Spencer e até mesmo com Karl Marx - a pretensão desse último

\footnotetext{
${ }^{9}$ Acontece que a principal obra de Karl Popper (1902-1994), "A Lógica da pesquisa científica", publicada em alemão, no outono de 1934, só aparece em inglês, em 1959, sob o título de Logic of scientific Discovery; e, em português, em 1974, sob o título "A lógica da pesquisa científica". Thomas Kuhn (1922-1996) publica o seu mais-que-famoso ensaio "A estrutura das revoluções científicas", em inglês, em 1962. Estes dois homens conheceram-se e tiveram mais de duas décadas de debate sobre a Filosofia da Ciência. Embora Kuhn fosse vinte anos mais jovem do que Popper, este último viveu 16 anos a mais que o primeiro e foi produtivo até o final de sua vida.
} 
nunca fora a de fazer uma ciência da sociedade - não conseguiu apresentar consensos teóricos mínimos em torno dos objetos da pesquisa social, sejam eles quais forem. Max Weber, mesmo tendo proposto uma sociologia de cunho cultural, na tradição do historicismo alemão, e com uma importante marca epistemológica hermenêutica, não angariou, em torno da sua teoria sociológica, consenso que fosse maior ou menor do que aquele obtido pelos demais "clássicos" (excetuando-se Marx, talvez), nas diferentes regiões por onde a sociologia despontou e se desenvolveu. Este fato, por si só, fragilizou a sociologia (como ciência) quando comparada às ciências naturais (tradicionais), cujos consensos sempre foram maiores que as controvérsias ${ }^{10}$, pelo menos até as primeiras décadas do século XX. Este estado de coisas, ou seja, a debilidade teórico-epistemológica (em última instância, de fundamento) da sociologia, por um lado e, a robustez das ciências naturais, por outro lado, foi a tônica do debate epistemológico durante boa parte do século XIX, adentrando o século XX, e não perdendo fôlego até os dias de hoje.

A questão que envolve as ciências sociais e as ciências naturais, quanto à peculiaridade de seus objetos, está vinculada de modo significativo ao momento histórico da gênese da cada uma dessas ciências. Quando a sociologia, por exemplo, foi concebida como Ciência, as ciências naturais (a física, a química e mesmo a biologia) - de modo muito próximo ao consenso - acreditavam que os fenômenos (todos eles) repousassem sobre leis que necessitavam ser "(des)cobertas" e que os métodos indutivo

\footnotetext{
${ }^{10}$ Embora o estudo das controvérsias e não dos consensos seja mais atrativo para a investigação científica em diferentes disciplinas, sobretudo para a história, a sociologia e a antropologia da ciência, os consensos nas ciências naturais são inúmeros; para exemplificar, citaremos apenas alguns: a física clássica, com as leis do movimento, propostas por Isaac Newton; a física relativista, com a relação de interdependência espaço-temporal, proposta por Albert Einstein; a biologia, com a teoria da evolução e as noções de adaptação e seleção natural, proposta por Charles Darwin; a termodinâmica, com relação às leis sobre conservação de energia e o conceito de entropia, esboçadas por Sadi Carnot e Rudolf Claussius; a genética, com relação ao modelo da dupla hélice da molécula de DNA, etc. Se tomarmos os problemas científicos específicos, no sentido da "ciência normal" de Kuhn, então os consenso são milhares.
} 
e dedutivo, aliados ao experimentalismo, quando bem aplicados, eram suficientes para revelar toda a realidade natural ${ }^{11}$.

A Sociologia e "seu objeto", no entanto, contrariamente ao objeto das ciências naturais, nasceram complexos (caóticos?); uma complexidade muito semelhante, do ponto de vista epistemológico, à que tem estado cada vez mais presente na pauta dos debates da hard science, sobretudo a partir da segunda metade do século XX, com a crise do determinismo, com os avanços dos estudos de probabilidade, da relatividade e dos sistemas complexos ${ }^{12}$. O inimaginável aumento das controvérsias científicas e a dificuldade em continuar encontrando as "leis universais" têm equiparado a atual complexidade das ciências naturais à das ciências sociais. Se, por um lado, a sociologia - nosso exemplo no âmbito das ciências sociais - institucionalizou-se num momento (finais do século XIX) em que o método das ciências naturais - tanto na física, como na química e na biologia - apresentava resultados importantes, por outro lado, coincide, também, com o momento em que, na própria "ciência da natureza", esse método começara a mostrar sinais de esgotamento, justamente pelas "descobertas" de uma série de fenômenos, que se mostravam impossíveis de serem determinados. Esse desencaixe, essa (des)sincronia epistêmico-metodológica entre o nascimento das ciências sociais e o estágio de desenvolvimento em que se encontravam as ciências naturais, acreditamos, vai ter consequências importantes no desenvolvimento e aprofundamento da dicotomia entre essas "duas ciências" que, quase um séculos mais tarde, C. P. Snow ([1959] 1995) chamou de "Duas Culturas" em sua célebre conferência.

\footnotetext{
11 Sobre esta afirmação e esse debate ver: Pérez (2003); Moura (2001); Omnès (1996); Schwartz (1992); Losee (1979).

${ }^{12}$ A crise dessa visão determinística vai acontecendo muito gradualmente durante o século XIX. Pensadores como Maxwell, Bolzmann, Gibbs, cujos trabalhos avançaram tremendamente no campo da probabilidade, tornaram-se conhecidos na segunda metade do século XIX e influenciaram tanto a teoria da relatividade, como a noção de incerteza de Heisenberg. Sobre aspectos históricos da crise do determinismo ver lan Hacking (2012; 2005).
} 
No âmbito da própria sociologia, a cisão entre as ciências sociais e as ciências naturais estabeleceu-se com a proposição feita por Wilhelm Dilthey - a diferença entre as Geisteswissenschaften (ciência do espírito) e as Naturwissenschaften (ciências da natureza) -, em sua clássica obra "Introdução às ciências do espírito", de $1883^{13}$, que trata de fundamentar o estudo da sociedade e da história". Essa dicotomia proposta por Dilthey, de certo modo festejada em larga medida pela sociologia - e hoje ainda muito pouco criticada -, teve um papel fundamental para que essas "duas culturas", no sentido proposto por Snow (1995), fossem instituídas e perpetuadas até os dias de hoje $\mathrm{e}^{14}$.

Com o intuito de deixarmos nossa perspectiva sobre esse período histórico da epistemologia, que se estende até meados do século $X X$, de modo mais sumarizado, sistematizamos alguns de seus principais aspectos e reflexos na forma de produção do conhecimento científico:

a) As ciências naturais desenvolveram-se, paulatinamente, até meados do século XIX, através do método observacional (principalmente), crendo que o "natural" fosse mais simples do que de fato o é. Acreditava-se que, com a observação e com a experimentação - ambas bem amparadas pela razão, nos termos da lógica aristotélica - descortinar-se-iam todas as leis que compunham o mundo natural. Assim, guardou-se certa ingenuidade com relação à "profundidade" (ou complexidade) da própria realidade ("natural" ou "não-humana") dos objetos do mundo.

b) Quando do nascimento da sociologia, as ciências naturais, já com o seu método bem estabelecido há mais de um século, haviam des-

\footnotetext{
${ }^{13}$ Neste artigo estamos utilizando a edição espanhola, cujo título é "Introducción a las ciencias del espíritu: en la que se trata de fundamentar el estudio de la sociedad y de la historia", de 1949.

${ }^{14}$ Nem mesmo Comte, considerado o pai do Positivismo, em seu "Curso de filosofia Positiva" ([1830-1842] 1983), publicado cinquenta anos antes da obra de Dilthey, propõe uma separação entre as ciências naturais e as ciências sociais, quando estrutura a "Lei dos três estágios"; ao contrário, lá a sociologia é a síntese evolutiva de toda a complexidade apresentada pelo desenvolvimento das demais ciências.
} 
coberto algumas regularidades (leis) que, em termos pragmáticos, faziam o mundo "funcionar", mostrando-se extremamente alvissareiras. Não deveria ser estranho que seu método fosse estendido às ciências sociais para a obtenção do mesmo êxito.

c) As ciências sociais, entretanto, nascem tendo como "objeto" de Conhecimento algo de extrema complexidade: o fenômeno social. A crescente dinâmica dos sistemas sociais não se deixava apreender, desde o início, por uma abordagem metodológica de caráter linear, como fora possível, em diferentes momentos, no caso das ciências naturais.

d)Ciências da natureza e ciências sociais, no último século (e cada vez mais), têm apresentado graus de complexidade muito semelhantes, pois têm sido vistas como "sistemas dinâmicos"; assim, seus objetos não conseguem (e cada vez menos) ser afrontados por uma epistemologia exclusivamente analítica e linear.

e) Do ponto de vista epistemológico, na contemporaneidade, é necessária aprofundada reflexão sobre a relevância da cisão entre as ciências sociais e as ciências naturais - e até mesmo o impedimento que tal prática traz -, posto que seus "objetos" de conhecimento estão cada vez mais indissociáveis.

O modelo como a Ciência se desenvolveu durante a Modernidade, além de suas características lineares - realística, causal e determinística ${ }^{15}$ também obedeceu à proposição analítica cartesiana, ou seja, a de dividir o todo em quantas partes necessárias fossem, para assim, reduzir também

\footnotetext{
${ }^{15}$ Tais termos, os quais colocamos juntos, foram objetos de acalorados debates epistemológico, inclusive sobre a polissemia de seus significados. Não podemos aqui discuti-los, pois foge à pretensão do artigo. Entretanto, brevemente, destacamos que estamos utilizando o termo "realismo", "realístico", ou "realismo epistemológico", no sentido, descrito por Schlick (1975b, p. 48), que diz: "Quanto a isto, parece haver duas correntes: a do "Realismo" que crê na realidade do mundo externo...". Também não vamos entrar na discussão popperiana (2010, p. 217) sobre a tese de que "o realismo não é demonstrável nem refutável". Sobre "causalidade" e "determinismo", estamos empregando no mesmo sentido discutido por Schlick (1975a, p. 9-43; Hacking, 1999, p. 17-30).
} 
as dificuldades. Neste sentido, no Ocidente, principalmente, o conhecimento tendeu a se constituir na forma de disciplinas estanques e, no sentido proposto por Bourdieu (2000), como subcampos, relativamente autônomos, com relação ao próprio campo científico.

Fato é que a disciplinarização do conhecimento passou a ser confundida (e concebida) como uma "lei natural". Esqueceu-se que o conhecimento científico "disciplinar", não é um "dado natural", no sentido clássico que inclui a sua imutabilidade. As disciplinas que compõem o conhecimento científico não se encontram "dadas na natureza", mas, sim, constituem-se numa "invenção" (construção) social, numa teorização sobre o conhecimento e não a própria realidade empírica. Portanto, a atual cartografia do conhecimento pode - em muitos casos deve - ser reorientada; contrapondo-se ao à abordagem analítica disciplinar.

Assistimos, no século XX, principalmente a partir da sua segunda metade, não apenas a um aumento de complexidade do conhecimento, como se menciona frequentemente, mas sim, a um aumento da complexidade (da dificuldade) para que se conheçam os fenômenos contemporâneos. Paralelamente, os "objetos de conhecimento" mostraram-se - todos - mais complexos à medida que se faziam conhecidos. É como se em todo o conhecimento somente fizéssemos adentrar níveis cada vez mais sofisticados de complexidade, em todo e qualquer campo disciplinar. Portanto, não foi a "realidade" dos objetos que se tornou mais complexa, mas o próprio avanço do conhecimento que desvelou níveis crescentes (talvez infinitos) de complexidade ${ }^{16}$; níveis esses que, se já não existentes desde sempre, são propiciados pela interação dos objetos com o próprio "ato" de conhecer. Por esse motivo, quando falamos em complexidade, em aumento da complexidade, em paradigma complexo, caímos num certo

\footnotetext{
${ }^{16} \mathrm{~A}$ isto Niklas Luhmann (1998) tem chamado de redução de complexidade, mediante complexidade.
} 
vazio conceitual; num conceito repleto de conteúdo, que aceita todo e qualquer conteúdo, como se fosse um significante repleto de significado (os estruturalistas diriam: um significante que tudo significa, ou um significante vazio), sobretudo a partir de uma perspectiva epistemológica.

De fato, explicar a complexidade tem sido uma tarefa difícil ${ }^{17}$. Os motivos dessa dificuldade são variados e mesmo o enunciado dessas razões não é fácil. Enumeramos alguns pontos que têm tornado a compreensão e apreensão da noção de complexidade pouco acessível:

a) A complexidade não aceita qualquer perspectiva disciplinar, fazendo-se transbordar aos limites da disciplinarização do conhecimento. Em outros termos, as práticas disciplinares do conhecimento são incompatíveis com a complexidade ${ }^{18}$, posto que tais práticas "funcionam" somente para a solução de "problemas lineares", os quais acontecem exclusivamente no âmbito disciplinar.

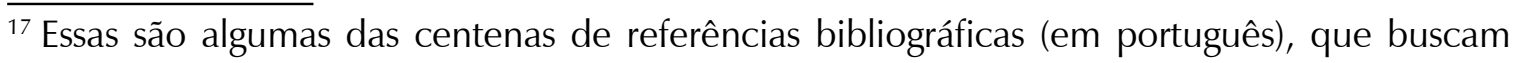
uma discussão sobre a complexidade, a partir de diferentes enfoques, sejam eles filosóficos ou científicos; epistemológicos ou ontológicos, de forma interdisciplinar: Bertalanffy (2011); Capra (1996, 1990); Horgan (1998); Lorenz (1996); Luhmann (1998); Morin (2000, 1987, 1984); Pessis-Pasternak (1993); Nussenzveig (1999); Prigogine (1996). Michel Baranger, do Centro de Física Teórica ligado ao Instituto de Tecnologia de Massachusetts, bem descreve as razões pelas quais a Teoria do Caos se constitui num imbróglio para as hard sciences, diz ele: "Caos é a revolução anticálculo. O caos é a redescoberta de que o cálculo não tem poder infinito. No sentido mais amplo possível, o caos é a coleção daquelas verdades matemáticas que não têm nada a ver com o cálculo. E por isso é desagradável para os físicos do século XX. Em termos de aplicações, a Teoria do Caos resolve uma grande variedade de problemas científicos e de engenharia, os quais não respondem ao cálculo. Não se está dizendo que o cálculo, a partir de agora, será considerado fora de moda e que se deve concentrar toda a nossa atenção sobre o caos. Não, o cálculo mantém todo o seu poder, mas este poder é limitado. Cálculo é apenas uma parte da verdade..." (p. 4) [tradução livre para este trabalho]. Disponível em: http://necsi.edu/projects/baranger/cce.pdf.

${ }^{18}$ Os exemplos são abundantes poderíamos pensar aqui na física relativista, na física subatômica, na teoria contemporânea da evolução, na atual teoria econômica que foca a globalização e busca desenvolver cenários de previsibilidade, na sociedade como um fenômeno, cujas teorias contemporâneas buscam apreender a sua dinâmica no tempo e no espaço; sua precariedade como fenômeno estável e as dimensões de contingência que impede toda e qualquer previsibilidade.
} 
b) Mesmo que a interdisciplinaridade tenha emergido em função do aumento da percepção de complexidade do conhecimento; isto é, tenha emergido a partir da necessidade de se compreenderem fenômenos não-lineares (como o social, por exemplo), os campos disciplinares estão demasiadamente institucionalizados, tanto do ponto de vista de poder (no sentido foucautiano), como das práticas disciplinares e epistemológicas - se é que essa separação é possível. c) Os fenômenos complexos têm "apresentado a realidade" como se essa estivesse "organizada" em múltiplas descontinuidades epistemológicas, exigindo um permanente aumento da capacidade epistemológica para apreendê-los. Essa capacidade (ou ferramenta) epistemológica - ampliada ou aprofundada - coloca-se avessa à estrutura disciplinar da Ciência que tem sido praticada majoritariamente, até os dias de hoje, inclusive no âmbito da sociologia.

d) A complexidade tem demonstrado que a "diferença" entre ciência da natureza e ciência social vem perdendo (finalmente) relevância frente às demandas socionaturais, cujos exemplos são inúmeros (aquecimento global, camada de ozônio, desmatamento desordenado, extinção de espécies, novas patologias e infecções globais, envelhecimento e aumento populacional, esgotamento de recursos naturais dado o modo de produção capitalista, etc.). Aos poucos se vai impondo a necessidade de recartografar o conhecimento disciplinar com a construção de sínteses cada vez mais necessárias, posto que os limites demarcatórios entre uma e outra ciência disciplinar estão cada vez mais borrados.

e) A complexidade impõe que se avance, também, com relação a certos "marcos epistemológicos", hoje canonizados e pouco revisitados (ou revisados) que, de certo modo, foram erigidos levando em conta estritamente a separação entre ciências da natureza e ciências 
Sociologias, Porto Alegre, ano 18,no 41, jan/abr 2016, p. 24-53

do espírito tais como: "lógica da pesquisa científica", "refutacionismo"; "revolução científica", "paradigma", "obstáculos epistemológicos", "duas culturas", "ciências naturais e ciências sociais" etc., e que já não atendem às necessidades da pesquisa contemporânea como atendiam há meio século (ou mais) atrás.

\section{A contribuição epistemológica oriunda da pesquisa sociológica à compreensão da complexidade contemporânea}

Mesmo a ciência tendo se desenvolvido, primordialmente nos séculos XVI/XVII, com pensadores que não apenas filosofavam sobre a ciência, mas ao mesmo tempo propunham formas de prática científica e efetivamente as executavam (tais como Isaac Newton, Galileu Galilei, René Descartes, Thomas Hobbes, John Locke etc.), a prática científica passou lentamente, até os dias de hoje, a se distanciar da prática filosófica, sobretudo nas ciências naturais, direcionando-se para uma certa "divisão do trabalho intelectual", em que os filósofos pensavam a ciência e os cientistas praticavam a ciência.

Essa cisão ou partilha disciplinar atingiu seu ápice nos séculos XIX e XX. Neste último, pelo menos até a primeira metade - como mencionamos anteriormente -, a epistemologia desmembrou-se da filosofia e passou a fazer parte das diferentes disciplinas, buscando reengrenar o fazer filosófico ao fazer científico, pelo menos no que se refere à fundamentação epistemológica. Nesse contexto, emergiu, então, uma espécie de descontinuidade entre a ciência que se propõe, a partir de uma perspectiva filosófico-epistemológica, e a ciência praticada e seus resultados obtidos. Só que, dessa vez, foi a efetiva prática da ciência que passou a orientar e exigir reformulações filosófico-epistemológicas. A observação feita por Deleuze e Guattari (1992, p. 17), bem ilustra essa afirmação: “A 
exclusividade da criação do conceito assegura à filosofia uma função, mas não lhe dá proeminência, nenhum privilégio (...) pois há outros modos de ideação que não têm de passar por conceitos, como o pensamento científico". O que os autores não disseram é que, na história e na filosofia da ciência recentes, são abundantes os exemplos nos quais a ciência propõe os conceitos os quais a filosofia "deve pensar".

Esse tem sido o mote - o permanente questionamento acerca de seus fundamentos e de seus métodos - das ciências sociais, em geral, e da sociologia, em específico, sobretudo a partir da segunda metade do século XX, mas que de certa forma (talvez mais timidamente) a acompanhou desde suas origens no século XIX. A partir de meados do Século XX, a sociologia passou, de forma decisiva, a dar uma efetiva contribuição ao arrefecimento de uma epistemologia de caráter não-linear (indutivista; realista; essencialista), tanto através dos estudos sociais da ciência (social sciences studies), uma escola já bem consolidada e de escala internacional, como através de diversas produções teóricas que estão sob uma mesma rubrica genérica de "Pós-estruturalismo/Pós-fundacionismo/Desconstrução".

As abordagens pós-estruturalistas, de um modo geral, desenvolvidas centralmente no âmbito das ciências sociais, trazem em si o questionamento de todo o fundamento último. O pós-estruturalismo, como ferramenta epistemológica, questiona tudo aquilo que ancora e estabiliza todo e qualquer fundamento, como um pensado último; como se o próprio fundamento não fosse uma proposta/aposta socialmente construída e aceita (pactuada) como tal. Ao criticar essa estabilidade, essa âncora, essa certeza última, Derrida (em um texto clássico) diz:

O centro [isto é, o fundamento] recebe sucessivamente, e de maneira regular, formas ou normas diferentes. A história da metafísica, tal como a história do ocidente, seria a história dessas metáforas ou dessas metonímias. A sua forma matricial seria (...) a determinação de um ser como presença 
em todos os sentidos dessa palavra. Poder-se-ia mostrar que todos os nomes do fundamento, do princípio ou do centro designaram sempre a invariante de uma presença (eidos, arché, telos, energia, ousia), (essência, existência, substância, sujeito) (Derrida, 1967, p. 101).

Não podemos esquecer que o pensamento de Jaques Derrida é diretamente tributário do estruturalismo francês, como teoria social, e sua crítica contribuiu de forma muito singular para boa parte da reflexão pós-estruturalista, não apenas como teoria social, mas também como importante filosofia francesa contemporânea. A Desconstrução não deixa de ser a síntese de dois movimentos epistemológicos importantes entre a ciência e a filosofia. Ao mesmo tempo em que ela se inspira criticamente no movimento estruturalista francês, das décadas de 1970/80, ela deixa cair sobre ele (o estruturalismo) os conteúdos da recepção nietzscheana que fez a filosofia francesa; a influência da filosofia da linguagem de Wittgenstein e outros ${ }^{19}$; a fenomenológica do "das Sein" (o ser-aí, o ser-no-mundo) de Heidegger ([1927] 1989) e sua radical perspectiva de uma pergunta pelo ser que sempre está imerso no permanente presente do mundo e da sua efervescente contingência ${ }^{20}$.

Não obstante toda tradição clássica, a desconstrução também resultou, de forma um tanto indireta, da confluência de intrincados debates epistemológicos e avanços obtidos pela ciência que se desenvolveram durante o século XX, de forma interdisciplinar. Nesse particular, talvez a Ciência, mais que a Filosofia, contribuiu para isto. Os avanços da física, tanto

\footnotetext{
${ }^{19} \mathrm{~A}$ linguagem sempre interessou a filosofia, entretanto entra em cena numa abordagem pós-estruturalistas e desconstrutivista, durante o século XX. Para uma discussão mais ampla da linguagem e de seu interesse pela filosofia, incluindo uma abordagem sobre a importância de Wittgenstein, ver Hacking (1999).

${ }^{20}$ Não se pode deixar de mencionar aqui que a desconstrução é tributária, em boa medida da leitura, da apropriação que a filosofia francesa fez da filosofia alemã, sobretudo aquela desenvolvida a partir de Nietzsche. Isto vale também para o pensamento de Michel Foucault, e de Deleuze. Para uma discussão mais aprofundada sobre essa recepção que, de certo modo se construiu numa certa "antropofagia" da filosofia alemã, pelos franceses, ver: Badiou (2013).
} 
a relativista como a quântica; os avanços da cibernética, particularmente com as noções de feedback e de auto-organização, propiciando, posteriormente, no início da década de 1970, a emergência do conceito de autopoiese, proposto pelos biólogos Humberto Maturana e Francisco Varela $(1995 ; 1997)^{21}$, passaram a questionar, sobretudo, a relação do sujeito (conhecedor) e do objeto (a ser conhecido) na construção do conhecimento.

\section{Uma epistemologia contra as assimetrias?}

Há aproximadamente 40 anos, imersas no ambiente epistemológico acima descrito, as teorias construtivistas emergiram com força nos estudos culturais, em especial nos estudos sociais em ciência e tecnologia (ESCT). Os princípios que subjaziam a esses estudos orientavam os pesquisadores para uma postura simétrica em relação às causas do conhecimento verdadeiro e falso (Bloor, 1991), atentando para a indissolubilidade dos contextos de produção e justificação do conhecimento (Latour, 1987). Tais posturas foram frutíferas em suas consequências epistemológicas.

Munidos desse espírito, muitos cientistas sociais, mas não só esses, desenvolveram uma série de estudos microssociológicos, tendo como contexto grandes centros científicos de produção de conhecimento (Knorr-Cetina, 1981) e contextos cuja produção de conhecimento convencionou-se chamar de tradicionais. É a partir desses distintos lugares de enunciação e vivências que se elaborou um menu conceitual potente, supostamente capaz de dar conta da construção cognitiva in situ e de sua circulação pelas mais remotas áreas da sociedade global. Tais estudos acabaram, também, por impactar a epistemologia e a teoria social (Lynch, 1993), embora o alcance desse impacto seja ainda difícil de mensurar.

\footnotetext{
${ }^{21}$ Para uma abordagem mais específica, tanto do ponto de vista histórica como epistemológiCo, ver: Rodrigues (2008; 2012; 2013) Rodrigues e Mendonça (2006; 2006a); Mendonça e Rodrigues (2008); Rodrigues e Neves (2012)
} 
Como se não bastasse o golpe desferido contra o stabilishment da epistemologia clássica, posteriormente, tais teóricos investiram contra o próprio cânone da concepção ontológica moderna, que tratava assimetricamente sociedade e natureza, desde, ao menos, René Descartes. Derivou-se daí a generalização do princípio de simetria formulado, por David Bloor, a partir da negação de qualquer ontologia que separasse de um lado "o social" e de outro "o natural". Princípios epistemológicos daí resultantes não poderiam mais recorrer nem a uma epistemologia naturalista e nem a outra de base puramente social, construtivista radical. Dessa postura, que rompia com os ESCT anteriores, emergiram novas formas de conceber a construção cognitiva dos fatos, as quais buscavam superar em especial os exageros construtivistas anteriores, desaguando, por exemplo, nas emergentes teorias pós-sociais (Latour, 2005).

Esses importantes e recentes turns no seio dos estudos sociais da ciência, em específico, e na epistemologia, de um modo geral, para além de suas divergências de momento, reflexivamente operaram sobre seus próprios contextos de construção teórica, cobrando de seus autores situados sustentação epistemológica ante a possibilidade de autorrefutação (Bloor, 1991). No entanto, reproduziram a intermitente assimetria entre o universal e o contextual, teorias do centro e teorias da periferia ${ }^{22}$. Tratou-se de uma contradição sutil, quando tais estudos afirmaram que a verdade científica é produto de ações práticas contextualizadas, sem considerar, no entanto, o ímpeto universalizante da teoria sociológica que afirmava isso. Daí decorre grande parte das críticas pós-coloniais ao projeto epistêmico pretensamente universal para as ciências sociais (Mignolo, 2008). Como, então, sustentar, reproduzir e fazer avançar teorias sociológicas, de modo a justificar tais princípios, centrais nas construções teóricas sociológicas mais atuais, a saber, a "simetrização" e a "contextualização"?

$\overline{{ }^{22} \text { Ver Neves (2014) }}$ e Law e Lin (2015) 
Essas interrogações buscam fazer emergir novas formas epistemológicas, para além das assimetrias "social" e "natural" (Castro, 1996), mas também para além da assimetria "centro/periferia" (Neves, 2014), que imperam na rede de circulação de conhecimento, quase sempre produzindo pretensões arbitrárias de universalização e epistemicídios. Tais trabalhos advogam pela necessidade de fazer emergirem novos princípios epistemológicos organizadores da construção teórica sociológica. Trata-se, portanto, de esforço epistemológico para simetrizar e contextualizar toda forma de teoria, superando o insistente paradoxo que atravessa os estudos sociais da ciência e a teoria social decorrente destes ${ }^{23}$.

\section{A complexidade e os giros ontológico e pós-colonial}

Uma das consequências do deslocamento do determinismo cientificista em favor da complexidade é uma reconfiguração da posicionalidade dos saberes locais em relação aos saberes acadêmicos em sua pretensão de universalidade. A reelaboração de posicionamentos epistêmicos em relação aos saberes locais tem tido particular relevância na chamada onda pós-colonial e na esteira da vertente decolonial da modernidade/colonialidade. Fecunda em denunciar o epistemicídio, essa corrente tem sido

\footnotetext{
${ }^{23}$ Para ilustrar a fecundidade de epistemologias desse tipo indicamos dois casos de reconstrução conceitual distante do contexto original de seu desenvolvimento. Primeiramente, o caso da categoria empírica "administração da relevância", cunhado por Knorr-Cetina (1981). Tal categoria, ao circular pela rede tecnocientífica, muda consideravelmente seu conteúdo heurístico dependendo do espaço ao qual se vincula, podendo ser completamente invertida em outros contextos, como apresentado por Neves e Lima (2012) em outro momento com a categoria "administração da irrelevância". O segundo caso é indicado por Medina (2013) e trata-se do conceito, discutido a partir da teoria do ator-rede (Latour, 2005) e da teoria dos campos (Bourdieu, 1999), de "tradução assimétrica", herdeiro direto das discussões hermenêuticas sobre interpretação e poder. Tal conceito se propõe a lançar luz sobre o conceito de apropriação de conhecimento e teorização em áreas de produção científica pouco institucionalizadas, notadamente, na suposta periferia da produção teórica. Neste contexto, há diferenças importantes em termos simbólicos e materiais em relação ao centro da produção teórica.
} 
menos feliz em fazer o subalterno falar no interior do santuário acadêmico com peças de nome e voz própria. Deslocamento, tradução, hibridismo, interstícios têm sido os recorrentes termos de uma renúncia intelectual em falar a partir da e para a subalternidade. As dificuldades para se fazer eclodirem lugares outros de enunciação, que não os já experimentados no interior do processo pós-estruturalista de desmoronamento do subentendido sujeito cartesiano do conhecimento, ficam reforçadas pela desconstrução pós-moderna das identidades. O discurso pós-colonial emergiu distanciando-se do essencialismo identitário do discurso anticolonial (Shohat, 2008). A demissão diante das possibilidades de se fazer ecoar uma alteridade radical no interior do discurso científico é um protocolo plenamente estabelecido de suspeita em relação a qualquer tentativa de escavação de identidades originárias.

A outra das mais importantes viradas epistêmicas recentes - o giro ontológico pós-construtivista - sugere-nos a ideia de que certos objetos, encontrados no campo, são capazes de deslocar perspectivas teóricas primeiras, porque eclodem como acontecimentos que fazem diferença; portanto, não apenas os humanos, mas também os objetos estão dotados de agência e historicidade com potência para obrigar o investigador a deslocar seus enquadramentos teóricos (Henare, Hoolbraad, Wastell, 2007). A consequência mais importante desse retorno da fé no objeto (não mais substancial, mas dotado de uma historicidade que a sociologia não consegue reconstituir sem outras disciplinas) é a remoção do imperialismo sociológico nas abordagens às condições de possibilidade do conhecimento. A sociologia do conhecimento se refaz como uma ciência ao lado de outras, procedendo a reconstrução de etnocientificidades.

Essa virada ontológica também sugere que as diferenças entre saberes modernos e não modernos talvez tenha mais a ver com a extensão das redes pelas quais circulam os enunciados do que com a problemática da ver- 
dade em sua potência de universalização (Latour, 2001). A questão é que, se os nossos trabalhos são partes das redes pelas quais circulam saberes, o modo como nos fixamos aos pontos de partida e chegada pode contribuir para interromper redes, encurtá-las ou, pelo contrário, para promover uma extensão inovadora. Nesse sentido, saberes locais podem emergir em redes tanto mais curtas porquanto as nossas pesquisas insistem em não seguir a circulação de enunciados em suas extensões mais longas. No limite, não existem redes curtas em si, mas encurtadas pelas análises. Talvez, o funcionamento de conjunto das ciências modernas tenha justamente o efeito interruptor que cria saberes locais no mesmo ato em que enunciados locais de laboratório (inclusive os sociológicos) são universalizados.

Poderíamos, então, para finalizar exemplificando essa exponenciação da complexidade, apontar direções de um possível encontro entre o giro decolonial e a virada ontológica pós-construtivista com relação à questão das identidades subalternas em suas interseccionalidades (de classe, gênero, raça/etnia)? O espaço se tornou curto, mas alguns apontamentos podem ser delineados.

Os dois deslocamentos epistêmicos, o pós-colonial e o ontológico, denunciam que a máquina acadêmica moderno-ocidental opera por desconexão entre porta-vozes e saberes locais de tal modo que os atores locais colonizados e seus descendentes nunca falam senão sob tradução, sendo localizados e "representados". Por exemplo, o discurso atravessado de jargões sociológicos, do líder indígena, do estudante quilombola ou da professora travesti que chega à universidade, supõe-se que seja um texto contaminado pelos discursos acadêmicos, portanto, de algum modo, "impróprio". Com essa disjunção, aprofunda-se a impotência diante do desafio de se pensar conceitualmente para além dos paradigmas ocidentais. Quais são as dimensões do discurso nativo que permanecem presentes no discurso cifrado pelos códigos ocidentais? Como se poderia continuar sendo nativo, 
se essa condição é sempre uma sedentarização em relação ao nomadismo do pesquisador? Pode o enunciado pertencer ao corpo enquanto acontecimento sem que a essa corporalidade lhe seja sempre subtraído o espírito? Se o enunciado não for apenas discurso, mas também regime de existência, pode eclodir na folha de papel, na rede discursiva que lhe confere sentido, mas também na boca carnuda atravessada por uma dor audível?

Os esforços de se desconstruir identidades concebidas como primordiais, totalizantes, homogêneas e fechadas expôs importantes dimensões relacionais (Hall, 2003) contrastivas e instrumentais (Barth, Kuper 1981) dos processos de afirmação identitários, porém deixou na sombra a forma como raça/etnia, gênero e classe eclodem a partir de e se fazem encarnar em corpos deixando traços físicos e não apenas esquemas de percepção (Wade, 2002). A pressuposição de que o simbólico é o plano mais importante de eclosão do fenômeno da identidade tem bloqueado modalidades de se construírem narrativas mais corporalizadas dos processos históricos de encenação de identidades, particularmente das identidades raciais. Ao alertarem para os perigos de se substancializarem as diferenças e se erigirem esquemas essencialistas, muitos dos conceitos e das categorias centrais às teorias construtivistas das identidades negligenciaram a análise de importantes dimensões do processo de incorporação enquanto encarnação do acontecimento identitário.

Um deslocamento de enfoques epistemológicos para abordagens mais corporificadas da imbricação entre corpo e cultura (Csordas,1994; Ingold, 2002) pode aproveitar-se da virada ontológica (Castro, 2012) que vem ocorrendo nas ciências sociais (Latour, 1995) para introduzir diferenciais metodológicos no criticismo pós-colonial. Então, poder-se-ia perguntar como escrita/fala e corporalidades eclodem em um ambiente acadêmico em processo de enegrecimento por conta, por exemplo, de políticas afirmativas. 
Duas opções metodológicas fazem-se particularmente importantes: a primeira é o cuidado de se atentar para outras agências, na eclosão dos acontecimentos, além daquela dos humanos, a começar pelo próprio corpo - desumanizar o corpo como um segundo capítulo, após a crítica pós-estruturalista ao humanismo ocidental. A segunda opção metodológica é a injunção de que acontecimentos sejam narrados no modo como eclodem enquanto corpos, portanto, trata-se de escapar ao construtivismo que confina o que está em jogo nas análises das eclosões identitárias ao plano da reconstrução das lutas de representações. Para além das intenções identitárias, os corpos são lugares de eclosão de falas numa política do corpo a corpo com um mundo de não apenas humanos e nem sempre revestido de representações. Depois da aparente antropomorfização da agência dos objetos, passa a estar, de forma complementar, em jogo, tomar os corpos humanos como lugar de eclosão/inscrição de falas. Corpos racializados eclodem como acontecimentos da mesma forma que objetos-mundos deslocam perspectivas acadêmicas ao fazerem diferença no modo como eclodem. No momento pós-discursivo, os enunciados pertencem tanto às redes de sentido quanto aos corpos que ajudam a fazer eclodir numa particular visibilidade. Seguir essa rede em sua máxima extensão é um política de sentido, ou seja, uma epistemologia política.

Léo Peixoto Rodrigues - Doutor em Sociologia pela Universidade Federal do Estado do Rio Grande do Sul-UFRGS. Atualmente é Professor Adjunto da Universidade Federal de Pelotas. $\triangle$ leo.peixotto@gmail.com

Fabrício Monteiro Neves - Doutor em Sociologia pela Universidade Federal do Rio Grande do Sul. Atualmente é professor da Universidade de Brasília. $\triangle$ fabriciomneves@gmail.com

José Carlos dos Anjos - Doutor em Antropologia Social pela Universidade Federal do Rio Grande do Sul. Pós-doutor pela Ecole Normale Superieure de Paris (2007). Atualmente é professor da Universidade Federal do Rio Grande do Sul 
Sociologias, Porto Alegre, ano 18,no 41, jan/abr 2016, p. 24-53

atuando na Pós-Graduação em Sociologia e Desenvolvimento Rural. Coordenador do Curso de Doutorado em Ciências Sociais da Universidade de Cabo Verde. $\triangle$ jcdosanjos@yahoo.com.br

\section{Referências}

1. BADIOU, A. La aventura de la filosofia francesa a partir de 1960. Buenos Aires: Eterna Cadência, 2013.

2. BARTH, F.; KUPER, A. Process and Form in Social Life: Selected Essays of Fredrik Barth. London, 1981.

3. BARANGER, M. Chaos, Complexity, and Entropy: A physics talk for non-physicists. Disponível em: http://necsi.edu/projects/baranger/cce.pdf.

4. BERTALANFFY, L. Teoría general de los sistemas. Espanha: Fundo de Cultura Econômico, 2011.

5. BLOOR, D. Knowledge and social imagery. Chicago: University of Chicago Press, 1991.

6. BOURDIEU, P. The social conditions of the international circulation of ideas. In: SHUSTERMAN, R. (org.) Bourdieu: a Critical Reader. Londres: Blackwell, 1999, pp. 220-228.

7. BOURDIEU, P. O poder simbólico. Lisboa: Difel, 2000.

8. CAPRA, F. A Teia da Vida. São Paulo: Cultrix, 1996.

9. CAPRA, F. O Ponto de Mutação. Círculo do Livro: São Paulo, 1990.

10. CASTRO, E.V. Transformação na antropologia, transformação da antropologia. Mana [online]. 2012, vol.18, n.1 [cited 2015-09-21], pp. 151-171 . Available from: < http://dx.doi.org/10.1590/S0104-93132012000100006>

11. CASTRO, E.V. Os pronomes cosmológicos e o perspectivismo ameríndio. Mana 2(2):115-144, 1996

12. CSORDAS, T. Embodiment and experience. Cambridge: Cambridge University Press, 1994.

13. COMTE, A. Curso de filosofia positiva. In: Os Pensadores. São Paulo: Nova Cultural, 1983.

14. DeleuZE, G; GuATTARI, F. O que é a Filosofia: Rio de Janeiro: Ed. 34, 1992. 
15. DERRIDA, J.A estrutura, o signo e o jogo no discurso das ciências humana. In: COELHO, E.P. (Org.). Estruturalismo: antologia de textos teóricos. São Paulo: Martins Fontes, 1967, pp. 101-123.

16. DILTHEY, W. Introducción a las Ciencias del Espíritu: en la que se trata de fundamentar el estudio de la sociedad y de la historia. Buenos Aires, México: Fondo de Cultura Económica, 1949.

17. FOERSTER, H. Las semillas de la cibernética. Gedisa: Barcelona, 2006.

18. GUPTA, A. Epistemología y ciencia social. In: VALERO, A.J. Sociología de la ciencia. EDAF: Buenos Aires, 2004. pp. 191-229.

19. HALL, S. Da diáspora: Identidades e mediações culturais. Belo Horizonte: Editora UFMG, 2003.

20. HENARE, A.J.M.; HOLBRAAD, M.; WASTELL, S. Thinking through things: theorising artefacts ethnographically. New York: Routledge, 2007.

21. HACKING, I. La domesticación del azar. Gedisa: Argentina 2012.

22. HACKING, I. El surgimiento de la probabilidad: un estudio filosófico de las ideas tempranas acerca de la probabilidad, la inducción y la inferencia. México: Gedisa, 2005.

23. HACKING, I.Por que a linguagem interessa à Filosofia. São Paulo: UNESP, 1999.

24. HEIDEGGER. M. Ser e Tempo. Petrópolis: Vozes, 1989.

25. HORGAN. J. O Fim da Ciência: uma discussão sobre os limites do conhecimento científico. São Paulo: Companhia das Letras, 1998.

26. INGOLD, T. The perception of the environment: essays on livelihood, dwelling and skill. London: Routledge, 2002.

27. KNORR-CETINA, K. Manufacture of Knowledge: an Essay on the Constructivist and Contextual Nature of Science. 1st Ed. Pergamon Press, 1981.

28. KUHN, T. Tensão Essencial. São Paulo: UNESP, 2011.

29. KUHN, T. O caminho desde a estrutura. São Paulo: UNESP, 2006.

30. KUHN, T. A Estrutura das Revoluções Científicas. São Paulo: Perspectiva, 1996.

31. LATOUR, B. Science in Action. How to Follow Scientists and Engineers through Society. Cambridge: Harvard University Press. 1987.

32. LATOUR, B. Os Objetos Têm História? Encontro de Pasteur com Whitehead num Banho de Ácido Lático. História, Ciências, Saúde. Manguinhos, II (1), pp. 7-26, mar-jun 1995. 
Sociologias, Porto Alegre, ano 18,no 41, jan/abr 2016, p. 24-53

33. LATOUR, B. A esperança de Pandora: ensaios sobre a realidade dos estudos científicos. Baurú (SP): Edusc, 2001.

34. LATOUR, B. Reassembling the Social: An Introduction to Actor-NetworkTheory. Oxford: Oxford University Press. 2005.

35. LAW, J.; LIN, W.-y. Provincialising STS: postcoloniality, symmetry and method. [online] 2015 Disponível em: http://www.heterogeneities.net/papers.htm. Acessado em 12/12/2015.

36. LORENZ, E. A Essência do Caos. Brasília: UnB, 1996.

37. LOSEE, J. O Homem e a Ciência: introdução histórica à Filosofia da Ciência. São Paulo: Ed. Universidade de São Paulo, 1979. v.5

38. LUHMANN, N. Sistemas Sociales: Lineamentos para una Teoría General. Rudí (Barcelona): Anthropos; México Universidade Iberoamericana: Santa fé de Bogotá: CEJA, Pontifícia Universidad Javeriana, 1998.

39. LYNCH, M. Scientific practice and ordinary action: ethnomethodology and social studies of science. Cambridge: Cambridge University Press. 1993.

40. MAGEE, B. As Ideias de Popper. São Paulo: Ed. Cultrix, 1979.

41. MANNHEIM, K. Ideologia e Utopia. Rio de Janeiro: Zahar Editores, 1982.

42. MATURANA. H.; VARELA. F. De Máquinas y Seres Vivos - Autopoiesis: la Organización de lo Vivente. Santiago do Chile: Editorial Universitária, 1995.

43. MATURANA. H.; VARELA. F.. De Máquinas e Seres Vivos - Autopoiese: a Organizacão do Vivo. Porto Alegre: Artes Médicas, 1997.

44. MEDINA, L. R. Objetos subordinantes: la tecnologia epistémica para producir centros y periferias. Revista Mexicana de Sociología 75, núm. 1 (enero-marzo, 2013): 7-28. 2013.

45. MENDONÇA, D.D.; RODRIGUES, L.P. (orgs) Pós-Estruturalismo e Teoria do Discurso: em torno de Ernesto Laclau. EDIPUCRS, 2008.

46. MIGNOLO, W.D. Desobediência epistêmica: a opção descolonial e o significado de identidade em política. Cadernos de Letras da UFF, no 34 , p. 287 324, 2008.

47. MORIN, E.; MOIGNE, J.-L. A Inteligência da Complexidade. São Paulo: Petrópolis, 2000.

48. MORIN, E. O Método. Portugal: Publicações Europa-América, 1987.

49. MORIN, E. O Problema Epistemológico da Complexidade. Lisboa: EuropaAmérica, 1984. 
Sociologias, Porto Alegre, ano 18,no 41, jan/abr 2016, p. 24-53

50. MOURA, C. Racionalidade e Crise: estudos da história da filosofia moderna e contemporânea. São Paulo: Discurso Editorial; Editora da UFPR, 2001.

51. NEVES, F.M. A contextualização da verdade ou como a ciência torna-se periférica. Civitas, v. 14, n. 3, set.-dez. 2014. pp. 556-574.

52. NEVES, F.M.; LIMA, J.V.C. As mudanças climáticas e a transformação das agendas de pesquisa. Liinc em Revista, v. 8, n. 1, p. 268- 282, 2012.

53. NUSSENZVEIG, H. M. (Org.). Complexidade \& Caos. Rio de Janeiro: UFRJ/ COPEA, 1999.

54. OLIVA, A. Racional ou Social: a autonomia da razão científica questionada. Porto Alegre: EDIPUCRS, 2005.

55. OLIVA, A. Ciência e Sociedade: do consenso à revolução. Porto Alegre: EDIPUCRS, 1999.

56. OMNÈS, R. Filosofia da Ciência Contemporânea. São Paulo: UNESP, 1996.

57. PALMA, H.A. De la concepción heredada a la epistemología evolucionista: un largo camino en busca de un sujeto no histórico. Revista Redes, v. 5 n.11 junho de 1998, p.53-79. Buenos Aires: Universidad Nacional de Quilmes.

58. PÉREZ, R. Existe um método científico? México: FCE, SEP, CONACYT, ECN, 2003.

59. PESSIS-PASTERNAK, G. (Org.) Do Caos à Inteligência Artificial. São Paulo: UNESP, 1993.

60. PLOTNITSKY, A. Epistemology and probability. Nova York: Springer, 2010.

61. POPPER, K. Textos escolhidos. Rio de Janeiro: Contraponto; PUC-RIO, 2010.

62. POPPER, K. Autobiografia Intelectual. São Paulo: Cultrix, Ed. Universidade de São Paulo, 1977

63. POPPER, K. A Sociedade Aberta e seus Inimigos. Belo Horizonte: Itatiaia; São Paulo: USP, 1974. v. 1 e 2

64. POPPER, K. A lógica da Pesquisa científica. São Paulo: Cultriz, 1974a.

65. PRIGOGINE, Ilya. O fim das certezas. São Paulo: Ed. Universidade Estadual de São Paulo, 1996.

66. REISCH. George A. Cómo la Guerra Fría transformó la Filosofía de la Ciencia: hacia las heladas laderas de la lógica. Bernal: Universidad Nacional de Quilmes: 2009.

67. RODRIGUES, L.P. Da fisiologia à Sociologia? Elementos para uma revisão da história teórica da sociologia sistêmica. Revista Brasileira de Ciências Sociais., v. 28, no. 82/jun. 2013. p 165-178. 
68. RODRIGUES, L.P. Notas Epistemológicas: Niklas Luhmann e a tradição Sociológica. Século XX, v. 2, no. 1 jan./jun. 2012.

69. RODRIGUES, L.P. Sistemas auto-referentes, autopoiéticos: noções-chave para a compreensão de Niklas Luhmann. Pensamento Plural. , v.3, 2008. pp.105- 120. 70. RODRIGUES, L.P. Introdução à sociologia do Conhecimento da Ciência e do Conhecimento Científico. Passo Fundo: Editora da UPF, 2005.

71. RODRIGUES, L. P.; MENDONÇA, D. (Orgs.) Ernesto Laclau e Niklas Luhmann: Pós-Fundacionalismo, abordagens sistêmicas e as organizações sociais. Porto Alegre, EDIPURS, 2006.

72. RODRIGUES, L.P.; MENDONÇA, D. A (des)estruturação das estruturas e a (re)estruturação dos sistemas: uma revisão epistemológica crítica In: RODRIGUES, L.P.; MENDONÇA, D. Ernesto Laclau e Niklas Luhmann: Pós-fundacionismo, abordagem sistêmica e as organizações sociais. Porto Alegre: EDIPUCRS, 2006a, pp. 35-67.

73. RODRIGUES, L.P.; NEVES. F.M. Niklas Luhmann: a sociedade como sistema. Porto Alegre: EDIPUCRS, 2012.

74. SCHLICK, M. Causalidade na física atual. In: Popper, Schlick e Carnapp. Coleção Os Pensadores, São Paulo: Abril Cultural, 1975.

75. SCHLICK, M. Positivismo e Realismo. In: Popper, Schlick e Carnapp. Coleção Os Pensadores, São Paulo: Abril Cultural, 1975

76. SHOHAT, E. Notas sobre lo «postcolonial» In: Mezzadra, Sandro et alii. Estudios Postcoloniales. Ensayos Fundamentales. Traficantes de Sueños, Madrid. 2008.

77. SNOW, C. P. As duas culturas. São Paulo: EDUSP, 1995.

78. SCHWARTZ Joseph. O Momento criativo: mito e alienação nas ciências modernas. Círculo do Livro. 1992.

79. STÄDLER, Friedrich. El Círculo de Viena. México. Universidade Autónoma Metropolitana, 2010

80. WADE, P. Race, Nature and Culture: an Anthropological Perspective. London: Pluto, 2002.

81. WIENER, N.; SCHADÉ, J.P. Cybernetics of the nervous system. Amsterdam, Londres, Nova York: Elsevier, 1965.

Recebido em: 26/01/2016

Aceite final: 10/03/2016 